\title{
mssaico
}

\section{As origens}

de Itabuna:

o mito e a

história

Ayalla Oliveira Silva ${ }^{1}$

\section{Resumo:}

Os estudos da história da região do sul da Bahia por muito tempo estiveram atrelados quase totalmente a uma narrativa memorialista regional. Neste trabalho, pretendemos iniciar uma reflexão da historiografia tradicional no que toca o tema da fundação de Itabuna. O objetivo central é analisar a própria dinâmica da historiografia local, tendo como hipótese que a mesma se solidificou a partir de representações políticas, econômicas e sociais de uma parcela da elite local ao longo da segunda metade do século XX e que vem se perpetuando, sem qualquer esboço de contestação pelas produções acadêmicas da história local, de cunho tradicional. Assim, o que se propõe é repensar as narrativas sobre as origens de Itabuna, considerando a importância do aldeamento de São Pedro de Alcântara em Ferradas, como marco da colonização daquele território na segunda década do século XIX.

Palavras-chave: narrativa memorialista; historiografia; Itabuna.

\section{Abstract:}

Studies in the history of the southern region of Bahia have long been almost entirely tied to a narrative memoir regional. In this work, we intend to initiate a reflection of traditional historiography regarding the issue of foundation Itabuna. The central objective is to analyze the dynamics of local history, with the assumption that it solidified from political representation, economic and social value of a share of the local elite over the second half of the twentieth century and that continues to exist without any attempt to challenge the most recent academic productions. So, what is proposed is to rethink the narratives about the origins of Itabuna, considering the importance of the village of San Pedro de Alcantara in iron, like March of the colonization of that territory in the second decade of the nineteenth century.

\footnotetext{
1 Graduanda do VIII semestre do curso de História pela Universidade Estadual de Santa Cruz - UESC, sob a orientação do Professor Doutor Marcelo Henrique Dias.

E-mail: ayallasilva@yahoo.com.br
} 
O esforço deste trabalho está voltado a promover uma reflexão da história das origens de Itabuna, destacando agentes e processos negligenciados pela narrativa tradicional. Neste sentido, se preocupa em fazer uma análise de conteúdo das publicações da narrativa da história de Itabuna mais relevantes, tendo como objetivo identificar os elementos que consolidaram o mito da história de fundação da cidade.

A análise em questão, não tem a preocupação de identificar onde e quando o mito de origem de Itabuna foi gestado, interessa apontar a sua consolidação a partir de alguns intelectuais da década de 1960, momento em que a cidade de Itabuna comemorava os seus cinqüenta anos de emancipação política. Os trabalhos publicados nesse período, os quais seriam os mais utilizados posteriormente por qualquer pesquisa que estivesse voltada a escrever sobre Itabuna, são: Documentário histórico ilustrado de Itabuna, de José Dantas de Andrade (1968); Terras de Itabuna, de Carlos Pereira Filho (1960); O jequitibá da Taboca, de Oscar Ribeiro Gonçalves (1960); e Firmino Alves - Fundador de Itabuna, de José Alves de Souza Freire (1963). Além dessas, serão analisadas obras posteriores à década de 60, bem como serão levantados fragmentos do jornal Diário de Itabuna e documentos do Arquivo Público do Estado da Bahia.

Diante das dificuldades em encontrar informação sobre os autores acima citados, salvo algumas recolhidas em notas de livros ou fontes hemerográficas, fica uma lacuna pela própria falta de trabalhos sobre os referidos autores. Embora suas obras sejam recorrentemente visitadas, não há um trabalho biográfico sobre esses memorialistas, ou informações mais precisas.

Seguindo o rastro de sua atuação no jornal Diário de Itabuna da década de 1960, podemos recolher em uma página ou outra, algumas poucas informações sobre a atuação social e política de alguns desses autores. Por exemplo, O diretor e proprietário do jornal Diário de Itabuna, Ottoni Silva, em uma nota do dia 14 de maio de 1960, parabeniza o escritor e jornalista Carlos Pereira Filho, autor de Terras de Itabuna e pontua sua atuação em defesa dos interesses da lavoura do cacau "(...) como procurador das associações que representam os interesses da lavoura cacaueira" (Diário de Itabuna, ano III, no698, 14 de maio de 1960), o que demonstra proximidade do intelectual à imprensa e certa articulação política do mesmo na região. Há ainda uma nota do mês de agosto do mesmo ano fazendo menção ao lançamento do livro de Pereira Filho: "Vá imediatamente a qualquer livraria local e adquira, por Cr\$150,00 apenas, o interessante livro TERRAS DE ITABUNA." (Diário de Itabuna, Quarta-feira, 17 de agosto de 1960, Ano III, n.o 730, p. 4).

Sobre a atuação profissional de José Dantas de Andrade, há o registro de uma nota que diz: "A história de Itabuna está sendo contada. Todos têm a palavra. Os contemporâneos 
de Tabocas vêm às nossas colunas e ao microfone da Rádio Clube de Itabuna, no programa do Dantinhas, para falar o que sabem." (Diário de Itabuna, 16 de julho de 1960, ano III, no739, $\mathrm{S} / \mathrm{P}$ ). O conteúdo da nota do jornal demonstra que o autor atuava diretamente na imprensa daquele período. É importante ressaltar que a Rádio Clube pertencia ao mesmo grupo do jornal Diário de Itabuna.

Sobre Oscar Ribeiro Gonçalves, se sabe que o autor foi prefeito na cidade de São Félix, no recôncavo baiano e escreveu O Jequitibá da Taboca por encomenda na ocasião das comemorações do cinqüentenário de Itabuna. O conteúdo da obra consiste no registro dos relatos orais de um antigo morador da cidade, Manoel Bonfim Fogueira. Já a respeito de José Alves de Souza Freire, sabe-se que sua obra é em parte de cunho afetivo, já que como neto do Comendador Firmino Alves, tido como fundador de Itabuna, teria a intenção de homenagear o avô.

A atuação de alguns desses intelectuais da década de 60 nos órgãos de imprensa, seja falada ou escrita, reflete a homogeneização dos discursos da escrita da memória e da atuação da imprensa sobre o caráter de progresso e modernização da cidade que tinha como percussores seus primeiros habitantes - os sergipanos. Demonstra ainda como esses memorialistas circulavam social e politicamente, visto que, os jornais eram importantes espaços de veiculação de ideologias e disputas políticas.

O jornal Diário de Itabuna foi fundado em 1957, tinha como diretor o jornalista Ottoni Silva e circulava no trecho Itabuna-Ilhéus e outras cidades menores como Itapé, Ibicaraí, Itapetinga, Buerarema, Juçari, Camacã, Coaraci, Banco Central. (RIBEIRO, 2010; p. 18).

A primeira parte deste trabalho se constitui da tentativa de estabelecer um diálogo entre a narrativa memorialista da origem de Itabuna, bem como a construção da identidade local e da historiografia, com discernimentos teóricos acerca da memória coletiva. A segunda parte estará pautada em analisar o conteúdo das obras apontadas no que se refere ao tema das origens de Itabuna, a partir do contexto de comemoração do cinqüentenário da cidade, um acontecimento importante para a emergência dessas obras e do conteúdo de reverência ao passado com o qual elas foram revestidas. Na terceira parte, serão apontados alguns elementos daquelas narrativas históricas responsáveis pela fixação da imagem dos grupos hegemônicos daquele período como herdeiros do trabalho de homens simples. E finalmente, será demonstrada uma tentativa da escrita da memória de construir, para Itabuna, uma identidade na qual a origem da cidade se confunde com a chegada dos imigrantes sergipanos. Nesse sentido, como se procura demonstrar, a escrita tradicional se esforça em estabelecer um distanciamento entre o primeiro núcleo de povoamento indígena, a aldeia de Ferradas, e Tabocas, onde se estabeleceram os primeiros sergipanos, no lugar da memória local. 
Na última parte do trabalho serão elencadas algumas observações sobre o caráter de permanência dos discursos gestados na década de 60 sobre as origens de Itabuna em obras mais recentes, inclusive acadêmicas, além de uma breve reflexão, a respeito da possibilidade de pensar o papel indígena no contexto de discussão das origens da cidade. Essa análise, se fundamenta na historiografia regional acadêmica mais recente, que tem se esforçado em problematizar a escrita da história da região, possibilitando assim novas perspectivas historiográficas sobre o sul da Bahia, bem como na documentação sobre o período colonial disponível no Arquivo Público do Estado da Bahia.

\section{Mito de origem, memória e identidade}

A produção memorialista regional, e aqui me refiro ao papel do que podemos chamar de uma elite intelectual local, sempre esteve voltada, consciente ou inconscientemente, a enaltecer nomes da elite política local, que assim afirma seu lugar de poder na memória oficial da cidade. O papel deste trabalho não é refutar essa produção, mas propor um diálogo entre a memória produzida e o fazer historiográfico.

Tratar as narrativas das origens de Itabuna consiste em situá-las nas discussões historiográficas sobre memória. A história local das origens de Itabuna, que nos remete sempre a um passado heróico, consiste no testemunho oficial de uma parcela da elite política e cultural local que representada pelos memorialistas da década de 60 , produziram sua representatividade social, através do testemunho histórico de cunho oficial.

Maurice Halbwachs salienta em sua abordagem que toda memória é coletiva, "memória social", "já que afinal de contas a história de nossa vida faz parte da história geral" (HALBWACHS, 2006, p.73). As lembranças que temos do passado, não são individuais e alheias as interferências externas, ou seja, elas não são apenas nossas, mas selecionadas pelo grupo do qual fazemos parte ou fora dele e atende as expectativas do contexto e do tempo vividos. Sobre os fatos históricos na memória coletiva o autor vai dizer:

Quando os evoco, sou obrigado a me remeter inteiramente á memória dos outros, e esta não entra aqui para completar ou reforçar a minha, mas é a única fonte do que posso repetir sobre a questão (...). Trago comigo uma bagagem de lembranças históricas, que posso aumentar por meio de conversas ou leituras - mas esta é uma memória tomada de empréstimo, que não é minha (HALBWACHS, 2006, p.72). 
Nesse sentido, situamos a memória oficial das origens de Itabuna, que atua como guardiã e perpetuadora dos fatos e personagens escolhidos para protagonizar os primeiros passos da colonização naquele território. A memória oficial transforma em memória coletiva, eventos históricos selecionados por grupos hegemônicos daquela sociedade, que através de símbolos e representações, transformam a memória coletiva do grupo em história. Imprimindo assim, mesmo nas gerações mais novas, lembranças de um passado da cidade que elas não viveram, mas que reconhecem e legitimam.

A memória da cidade, não é somente a presença do passado no presente através da transmissão feita por indivíduos dos fatos do passado. "A memória, essa operação coletiva dos acontecimentos e das interpretações do passado que se quer salvaguardar" (POLLAK, 1989, p. 9) é, sobretudo, uma construção feita pelos grupos hegemônicos que manipulam o que deve ser lembrado e esquecido ${ }^{2}$. Nesse contexto, as narrativas das origens de Itabuna ${ }^{3}$ são construções que delimilitam o lugar dos sujeitos e suas ações. Essas narrativas demarcam no passado de Itabuna o lugar dos desbravadores sertanejos, para assim legitimar a identidade coletiva da cidade a partir dos verdadeiros herdeiros do trabalho daqueles valentes homens.

Em Memória, esquecimento, silêncio, Pollak trás na sua abordagem um exemplo bastante pertinente a essa reflexão sobre memória coletiva, que foi a tentativa de destalinização, derrubada da visão de Stalin como herói dos pobres na União Soviética. A leitura de Pollak propicia enfatizar que destruir monumentos não era bastante para mudar uma concepção incutida na coletividade, só a partir do discurso de valorização das vítimas do stalinismo no lugar da figura de Stalin, se consegue dá início a uma reelaboração política em torno do stalinismo. Ou seja, enquanto os discursos não atingem a coletividade, não é possível construir uma memória coletiva ou desconstruir uma já posta.

A atuação política e social da escrita da história memorialista de Itabuna, enquanto agente de construção de uma memória coletiva oficial, reside no fato dessa produção atingir a coletividade através da recorrência da produção historiográfica regional a estas obras, que por sua vez, perpetua os discursos nelas gestados. Os discursos produzidos e organizados pelos grupos hegemônicos estão presentes não somente na historiografia, mas na literatura, nas comemorações cívicas locais, nas palestras escolares no contexto do aniversário da

\footnotetext{
2 Ver THOMSON, Alistair; FRICH, Michael; HAMILTON, Paula. “Os debates sobre memória e história: alguns aspectos internacionais". In: Usos e abusos da história oral. AMADO, Janaína; FERREIRA, Maristela de Moraes (Orgs.) 4 $4^{\mathrm{a}}$ ed. Rio de Janeiro: Editora FGV, 2001.

${ }^{3}$ Se constitui na sua maioria de obras memorialistas - escritos de intelectuais locais, ligados geralmente às elites políticas locais e que tiveram grande peso, no que diz respeito a consolidação e perpetuação do mito de origem de Itabuna.
} 
cidade, no teatro, nas aulas de história regional. Enfim, a memória heróica sergipana, daqueles que trabalharam e venceram, se confunde com a própria história local, através do trato da memória coletiva.

As representações de identidades construídas pelo jogo de se fazer lembrar e esquecer, assumido pela construção de uma memória coletiva sobre a história da origem de Itabuna, encontra solidificação nas narrativas históricas da cidade, as quais elaboram "um sistema de idéias-imagens de representação coletiva mediante o qual elas se atribuem uma identidade" (PESAVENTO, 1995, p.16), conferindo ao grupo dominante, representatividade oficial e hegemônica da sociedade e, concomitantemente, estabelece uma identidade pautada na perpetuação de seus interesses. Portanto, a tentativa de descortinar a narrativa histórica sobre as origens de Itabuna se funda em pensar sobre os personagens eleitos para protagonizar essa história. Logo, se faz necessário questionar os memorialistas principalmente os que escreveram no momento de comemoração do cinqüentenário de Itabuna -, os quais muito contribuíram para que os itabunenses ainda hoje atribuam a fundação da cidade unicamente à figura de Félix Severino do Amor divino e sua família que, "atraindo para perto de si seus parentes, lançara os fundamentos de uma próspera e futura cidade" (GONÇALVES, 1960, p. 32).

A abordagem deste trabalho se fundamenta na produção historiográfica regional mais recente, que aponta para possibilidades diversas das apresentadas oficialmente para pensar a história da região, e às reflexões suscitadas pela história cultural, de forma que podemos lançar mão de novas possibilidades de interpretação da história local que tem se apresentado de forma cristalizada pelos grupos hegemônicos.

O heroísmo sergipano foi o carro chefe das comemorações do cinqüentenário de emancipação política de Itabuna, os memorialistas, em especial os da década de 60, por sua vez, eram requisitados, seja por vínculos familiares ou políticos a prestarem homenagem a cidade, logo é compreensível o teor de reverência a um passado de pioneirismo sergipano. No entanto, essa construção memorialista dos anos 60, assume um caráter mitológico através da repetição do passado.

Acontece na história das origens de Itabuna, o que Pollak chama de enquadramento da memória. Através da narrativa histórica, seja nas obras publicadas, seja pela atuação nos órgãos de imprensa, os memorialistas da década de 1960, costuraram uma história politicamente favorável aos interesses de seu grupo social. Na trajetória da escrita local, a memória é recorrentemente reelaborada, mas, mesmo os discursos da escrita mais recente dessa história, não fogem aos elementos constitutivos da memória oficial, responsáveis por manter a coesão dos grupos hegemônicos da cidade. Retomando o primeiro ponto de 
análise dessa abordagem, a produção escrita da memória local no contexto do cinqüentenário se perceberá como se construía e articulava essa memória na escrita da história local.

\section{O cinqüentenário de Itabuna e a narrativa memorialista da década de 60}

Nada mais propício do que uma comemoração para fomentar a emergência de publicações de trabalhos. Com a chegada das festividades do cinqüentenário, em 1960, Itabuna viu surgir inúmeras obras, em sua maioria memórias escritas pela elite intelectual local, para homenagear a cidade e seus personagens ilustres. Muitas dessas obras sugerem tratar-se de encomendas que visavam garantir o lugar de prestígio de determinados grupos sociais.

A obra O Jequitibá da Taboca, de Oscar Ribeiro Gonçalves, escrita a partir dos relatos de Manoel Fogueira que, segundo as palavras do autor do livro, seria um dos pioneiros da história de Itabuna, trás esse caráter de obra encomendada no contexto das comemorações do cinqüentenário de Itabuna. De início, o prefaciador ${ }^{4}$ justifica futuras falhas detectadas na leitura do livro pelo fato do autor não ter tido tempo de organizar melhor a obra. Ele diz:

O Sr. Oscar Ribeiro, recolhendo os informes fornecidos pelo Sr. Manoel Bonfim Fogueira, não pretendeu fazer obra acadêmica, ou romanesca, ou crônica onde apenas palpitam as palavras cantantes de uma poesia sem bases reais. Por esta razão é provável que haja no livro alguns senões, alguns descuidos, que podem ser lavados à conta de pouco espaço de tempo que teve o autor para arrumar a história real de "O JEQUITIBÁ DA TABOCA" (GONÇALVES, 1960, p. 25-26).

É digna de nota, a fala do prefaciador ao se referir aos relatos de Manoel Fogueira como um material irrefutável, "pela verdade buscada e encontrada" (GONÇALVES, 1960, p. 26), o que nos sugere pensar sobre a preocupação dos escritos desse momento em personificar essa história de origem na figura dos desbravadores. Portanto, essa narrativa de cunho tradicional "utiliza a história como legitimadora das ações e como cimento da coesão grupal” (HOBSBAWM, 1997, p. 21).

\footnotetext{
${ }^{4}$ Plínio de Almeida - membro da Academia de Letras de Ilhéus.
} 
Para as elites, intelectual e política, é importante escrever uma história que legitime o seu lugar de poder frente à sociedade itabunense de maneira que se construa uma identidade social da cidade, voltada a ligar a imagem de homens do passado diretamente à imagem dos homens contemporâneos às obras publicadas daquele momento histórico. Os mesmos, foram considerados responsáveis por modernizar Itabuna que, desde a década de 30, vivencia, em seus espaços urbanos, práticas de modernização (CARVALHO, 2009). O discurso de civilização e progresso disseminado pela elite política da década de 30 , identificado por Carvalho (idem), está presente também na escrita memorialista da década de 60 sobre as origens de Itabuna. Ainda no prefácio de O Jequitibá da Taboca, Plínio de Almeida diz que o autor faz justiça aos herdeiros de um passado heróico, que deram a Itabuna o lugar de cidade da civilização e do progresso.

O fazer historiográfico nos compromete, no entanto, a ir além do que nos oferece as narrativas sobre a história das origens de Itabuna, nos debruçando sobre os discursos presentes nos conteúdos dessas narrativas, aqui entendendo a idéia de discurso como a que nos sugere Foucault: uma construção histórica feita por determinado grupo. ${ }^{5}$ Logo, a principal tarefa desse trabalho é identificar e analisar as tendências ideológicas presentes nessas memórias, geradoras que foram do mito de origem de Itabuna, através da repetição dessas narrativas. Nesse sentido, a análise da tradição das origens de Itabuna é importante por se constituir de "indicadores de problemas que de outra forma poderiam não ser detectados nem localizados no tempo" (HOBSBAWM, 1997, p. 20). Como, por exemplo, a ausência de outros agentes na história das origens de Itabuna:

Sozinhos, neste dito lugar ermo, como teriam eles contemplado aquele cenário? A mata, os caboclos e as feras eram seus únicos vizinhos, mas além outeiros hirsutos, reduzindo-lhes o horizonte, mais ao lado, corre o rio Cachoeira no meio do qual se divisavam ilhas com matas incultas, árvores cujas copas se entrelaçavam numa selvatiqueza rude; um céu pincelado de nuvens escuras quase sempre a chover. No deslumbramento desse espetáculo irradiava a luz solar como a flor da esperança na vibração da mocidade. Pois bem: nesse ambiente solitário habitava Felix Severino do Amor Divino e seu companheiro, o crioulo Manoel Constantino (GONÇALVES, 1960, p. 30-31).

O trecho acima trata, segundo o autor Oscar Ribeiro Gonçalves, dos primeiros momentos de contemplação por parte do imigrante Félix Severino do Amor Divino e seu

\footnotetext{
${ }^{5}$ Ver FOUCAULT, Michel. As palavras e as coisas: Uma arqueologia das ciências humanas. $8^{\mathbf{a}}$ ed. São Paulo: Martins Fontes, 1999.
} 
companheiro, Manoel Constantino, do lugar que seria futuramente Tabocas, o núcleo original da cidade de Itabuna. Uma narrativa mitológica e heróica que diria tratar-se de um romance se esta não tivesse a intenção de inscrever nas suas páginas a "verdadeira" história de Itabuna.

Ao contemplar essa narrativa, o leitor talvez se imaginasse no cenário, uma floresta intocada, a qual aqueles valentes e trabalhadores homens se dedicariam a tornar habitável. Na realidade, a região já era habitada por populações indígenas ${ }^{6}$ e colonos que dependiam da manutenção do aldeamento de Ferradas para limitar as ações dos chamados botocudos que transitavam naquelas paragens. Mas, a descrição feita pelo autor da citada memória sugere que os recém-chegados só encontraram a mata, animais ferozes e os caboclos, esses últimos descritos ao lado dos animais ferozes e da mata inóspita, verdadeiros obstáculos a serem superados.

Terras de Itabuna, do jornalista Carlos Pereira Filho, é uma obra de 1960, também escrita no momento comemorativo aos cinqüenta anos de emancipação política de Itabuna. Já na introdução do livro, o autor deixa clara a finalidade de sua obra: "Este trabalho tem a finalidade de homenagear a terra itabunense" (PEREIRA FILHO, 1960, s/p).

Um olhar para o passado e enxergamos, na Marimbeta, um núcleo de desbravadores. Em poucos anos este núcleo passou a chamar-se Tabocas, e logo em seguida Itabuna. O que é Itabuna, representada pela sua força social, econômica e política, todos sabem e todos conhecem pela posição que ocupa na colocação dos municípios brasileiros. Aos itabunenses poderíamos aplicar aquêles magníficos versos de Olavo Bilac, endereçados ao desbravador bandeirante:

Cada passada tua era um caminho aberto

Cada passo mudado, uma nova conquista

Teu pé, como de um deus, fecundava o deserto (PEREIRA FILHO, 1960, P. 14).

O memorialista, comungando do discurso das elites intelectual e política da década de 60 , se volta para o passado de Itabuna com o olhar de modernidade e progresso, que é próprio da sociedade daquele momento. Tal discurso cristaliza uma identidade itabunense pautada na figura dos sergipanos, representantes legítimos das origens de Itabuna.

Ainda comungando desse espírito de reverência ao passado, José Dantas de Andrade

\footnotetext{
6 Ver ANDRADE, João Cordeiro. Missões Capuchinhas na Comarca de São Jorge dos Ilhéus (18161875). Ilhéus, UESC, 2003.
} 
(1968) discorre sobre a destruição do que seria a primeira casa de Itabuna, dizendo que "seria de justiça, já que deixaram destruir aquela casa, que os filhos de Itabuna fizessem um movimento para se erguer no local um busto do desbravador sergipano, numa homenagem ao descobridor da cidade" (ANDRADE, 1968, p. 18). Temos aqui um bom exemplo de Construção de identidade através da edificação de símbolos de poder como suporte da memória.

No incansável dever a que se obrigavam os memorialistas da década de 60 de enaltecer a figura de José Firmino Alves, é que seu neto, José Firmino Alves de Souza Freire, se ocupou em homenagear o avô como desbravador de Itabuna, fazendo alusão da sua imagem:

Ao completar 100 anos de seu nascimento, a 25 de setembro de 1952, as autoridades e o povo de Itabuna, em colaboração com as autoridades dos Estados da Bahia e Sergipe e de vários municípios, lhe prestaram significativa homenagem, através de festas jamais assistidas nesta cidade (FREIRE, 1963, p. 22).

Na perspectiva de Sandra Pesavento sobre o jogo do lembrar e esquecer da memória “(...) as pessoas são ensinadas a lembrar e a esquecer, fazendo com que determinados acontecimentos não sejam considerados importantes ou mesmo que não tenham acontecido" (PESAVENTO, 2005, p. 96). Quando falamos do momento em que os memorialistas escrevem, podemos perceber que há memórias a serem esquecidas, porém, há outras que são maciçamente revisitadas pela escrita local.

O Diário de Itabuna, no mês de julho de 1960, mês do cinqüentenário, dentre as matérias publicadas fazendo referência à história da cidade, veiculou uma, intitulada: Sergipe e o Cinqüentenário. O colunista anônimo chamava a atenção para a necessidade de um convite oficial ao poder público sergipano para participar das festividades, fazendo alusão aos festejos do centenário de Firmino Alves, ocasião na qual o Estado de Sergipe teria feito questão de marcar presença.

A propósito das festas do cinqüentenário de Itabuna, destas colunas lembramos de uma feita à Comissão dos festejos a necessidade de um convite oficial ao Governo e ao Legislativo Sergipano.

Nos reportamos ao brilho dado as festas do centenário do nascimento de Firmino Alves, fundador da cidade, quando Sergipe mandou uma enbaixada composta de Deputados e jornalistas. Com ela veio também a bandeira sergipana pertencente ao Instituto Histórico de Aracajú, a qual, por 
solicitação de Itabuna foi concedida para as fetividades por nímia gentileza de seu Presidente e fez aqui parte no desfile, carregada por elementos representativos da colônia sergipana.

Não é demais pois, lembrarmos mais uma vez a conveniência do convite, porque nessa festa Sergipe tem o seu quinhão muito importante.

O sergipano foi um desbravador deste grande Município que é hoje Itabuna, orgulho da Bahia. Participou das lutas e canseiras, sem o que não estaríamos hoje, orgulhosos e satisfeitos comemorando uma data que nos é rara mostrando o que fizemos nestes cinqüenta anos de cidadania e o que podemos fazer para o futuro, com o exemplo dado pela bravura e destemor dos pioneiros que vieram do Estado vizinho trabalhar para nossa grandeza.

Reforçando assim o nosso apelo trazemos ao conhecimento público como repercutiu naquela época em Sergipe o centenário de Firmino Alves. Fazendo com que na Assembléia Legislativa daquele Estado o Deputado Filadelfo Dória, apresentasse um requerimento, [seundado] pelo Deputado Joaquim Fontes e aprovado por toda Assembléia, cujo teor é o seguinte:

“Deputado Filadelfo Dória - Sr. Presidente: No dia 25 do corrente mês, a cidade de Itabuna, do Estado da Bahia, comemorará com excepcional festejos o centenário de nascimento do seu fundador, o sergipano José Firmino Alves.

É uma justa homenagem que os bahianos prestam ao espírito progressista dos sergipanos. (...) considerando a necessidade de Sergipe participar dos festejos aludidos se fazendo representar;

Considerando que o Poder Legislativo de Sergipe não deve ficar indiferente àquelas homenagens.

\section{REQUEIRO}

Que ouvido o plenário e sendo aprovado, digni-se V. EXcia. Designar uma comissão desta Assembléia para representá-la nas festas do centenário de José Firmino Alves, na cidade de Itabuna, no dia 25 do corrente mês.

Sala das Sessões, 18 de setembro de 1952.

As.) Filadelfo Doria

Joaquim Fontes"

Fortes razões temos assim para insistir no nosso apelo e estamos certos de que a Comissão tomará as providências necessárias para o convite lembrado (DIÁRIO DE ITABUNA, Sexta-feira, 1ㅇ de julho de 1960, Ano III, n.․730, S/P).

O teor da matéria é contundente e apelativo ao reproduz mais uma vez o discurso de se estabelecer uma relação direta, determinante e definitiva entre as origens de Itabuna e os sergipanos. Esse discurso da imprensa está em consonância com a escrita dos livros 
publicados naquele momento, visto que a mesma fazia parte da elite intelectual local. Isso fica evidente em uma nota em que Ottoni Silva, lembra de um pedido do autor de Documentário Histórico Ilustrado de Itabuna: "Dantinhas quer que eu vá escrevendo, vez em quando, até o dia 28 de julho, sobre Itabuna do passado" (DIÁRIO DE ITABUNA, 4 de junho de 1960, Ano III, n. 714, p. 06). Esse passado estava sempre povoado dos valores da elite de Itabuna daquela época, ou seja, da década de 60, calcados que estavam nos ideais de civilização e progresso, partilhando do discurso desenvolvimentista do país naquele período.

\section{O desbravador de Itabuna, homem simples e trabalhador}

De acordo com Mahony ${ }^{7}$, depois de sucessivas crises externas e internas pelas quais passou a economia regional baseada na monocultura do cacau, se estabelece um alto índice de desemprego na região sul da Bahia. Naquele contexto, os trabalhadores haviam recomeçado a se organizar sindicalmente, sob liderança do Partido Comunista Brasileiro (PCB). No final da década de 1950, o Ministério do Trabalho brasileiro reconheceu a União dos Trabalhadores Rurais de Itabuna e Ilhéus, ressaltando que seria a única organização rural da Bahia a receber esse reconhecimento. O que nos permite refletir sobre o papel dos memorialistas de reforçar uma identidade local pautada no esforço de homens simples e dispostos ao trabalho.

Não podemos deixar de reconhecer, reverenciar e homenagear os bravos sergipanos que foram bandeirantes, pioneiros, desbravadores, muitos deles heróis anônimos. Preito de gratidão e justiça a todos que, desta ou daquela maneira e em qualquer tempo, foram colaboradores na fundação, construção e civilização da cidade de Itabuna e da lavoura cacaueira, hoje uma das principais fontes de divisas do país (FREIRE, 1963, p. 25-26).

As elites política e intelectual na década de 1960 reafirmavam a todo tempo que seus antecessores trabalharam muito e que passaram por muitas dificuldades para que eles herdassem os frutos do suor do seu trabalho. Podemos dizer, então, que essas elites viam no trabalhador rural organizado certa ameaça social e, munidos de uma narrativa tradicional, se voltavam para um passado pioneiro, a fim de legitimar o seu lugar de poder.

\footnotetext{
7 Ver MAHONY, Mary Ann. Um passado para justificar o presente: memória coletiva, representação histórica e dominação política na região cacaueira da Bahia. In: Caderno de Ciências Humanas Especiaria. V. 10, n.o 18, julho-Dezembro, 2007, p. 739-795. Trabalho que pesquisa a utilização da mão de obra escrava na lavoura cacaueira do sul da Bahia e reflete a relação das disputas políticas da região com a escrita memorialista do "pioneirismo heróico".
} 
Em Terras de Itabuna, Carlos Pereira Filho assim define a herança do pioneirismo heróico dos que representavam os grupos hegemônicos da sociedade cinqüentenária itabunense: "Por muitos anos esses homens trabalharam, anonimamente, humildemente, bravamente, derrubando matas, fazendo roças, plantando cacau, acumulando riquezas" (PEREIRA FILHO, 1960, p. 30). A idéia de Pereira Filho é corroborada por Oscar Ribeiro Gonçalves, que diz: "Estes homens de alma agrícola procuraram terras férteis onde melhor pudessem conseguir um lugar debaixo do sol, para dissiparem os males sofridos em outras regiões." (GONÇALVES, 1960, p. 27).

Dessa maneira os autores justificam que a riqueza construída pelos grupos dominantes se pauta na herança de trabalho dos seus antepassados, aproximando a figura dos ditos desbravadores à do trabalhador rural. A imagem do homem trabalhador é exaltada em um momento de ascensão do sindicato rural, como lembrou Mahony, pois essas elites temiam as reivindicações de direitos trabalhistas por parte desta instituição.

Uma nota do Diário de Itabuna, de 1960, destaca a figura do autor de Terras de Itabuna como um homem voltado a defender os interesses da lavoura cacaueira, demonstrando que os intelectuais do sul da Bahia cultivavam estreitas relações com os interesses políticos e econômicos da região:

Contrariando o espírito modesto de um grande trabalhador, nosso companheiro Carlos Pereira Filho, mesmo com pequeno atraso, vimos cumprimentá-lo, hoje (...) em nosso nome (...) como ainda em nome da lavoura cacaueira, de quem se constitui um dos mais ardorosos advogados, não perdendo tempo, não tendo cansaços, toda vez que há necessidade de uma ação urgente, enérgica, como procurador das associações que representam os interesses da lavoura cacaueira (DIÁRIO DE ITABUNA, 14 de maio de 1960, Ano III, n.o 698, p. 01).

Na narrativa histórica de Ilhéus, o jornalista Carlos Pereira Filho é citado, por Mahony, como opositor à idéia posta pela narrativa tradicional vigente, que contava a história da lavoura cacaueira ligada ao trabalho dos desbravadores, ocultando a utilização da mão de obra escrava. Em Terras de Itabuna, diferentemente do que fez na narrativa sobre Ilhéus, o autor reverencia os chamados desbravadores como os precursores de uma cidade notável, representante do progresso no Estado da Bahia.

Seguindo esse raciocínio, poderíamos sugerir que tal narrativa representa um esforço da memória local para distanciar o passado de Itabuna do passado de Ilhéus que, segundo Pereira Filho, teria edificado seus cacauais nas práticas arcaicas da antiga aristocracia. Em 
Ilhéus, Terra do cacau, afirma que, naquela localidade, a lavoura cacaueira teria nascido ao lado dos engenhos de açúcar ${ }^{8}$, fazendo menção à presença do trabalho escravo na implantação de ambas as lavouras. O autor afirma em sua abordagem sobre llhéus que a antiga lavoura açucareira e a nova lavoura que se estabeleceu no final do século XIX e início do XX, a lavoura cacaueira, teria sua vitalidade ligada ao trabalho escravo. Enquanto na narrativa sobre Itabuna demonstra um movimento diferente na implantação da lavoura do cacau: em Terras de Itabuna, confere ao imigrante sergipano a plena responsabilidade pela implantação da cultura do cacau.

\section{Tabocas X Ferradas: a idéia de civilização grapiúna}

O esforço da memória local em estabelecer um discurso de modernidade para Itabuna não foi gestado na década de 1960, pois, nesse momento, contexto histórico do cinqüentenário, a narrativa da memória procurou consolidar o que já havia sido proposto há década pelos grupos hegemônicos. Desde a década de 1930, "as modificações urbanas realizadas em Itabuna paralelamente produziram uma noção de civilidade pautada em comportamentos estabelecidos pelos agentes do poder público" (CARVALHO, 2009, p. 15). As elites de 60 se utilizam desse discurso para dizer que o caráter de modernidade e civilização conferido à Itabuna se devia ao passado, quando os pioneiros deram as necessárias condições para que a cidade progredisse.

Nas narrativas desse momento, dificilmente encontraremos referências aos indígenas da região, principalmente aos aldeados. Quando estes aparecem na narrativa tradicional é como entrave à civilização e ao progresso de Itabuna. Sendo assim, talvez não seja forçoso dizer que essa escrita se ocupa em promover um distanciamento entre Tabocas (berço da civilização grapiúna) e Ferradas (lugar de povoação de índio). Há um discurso repetitivo de que Itabuna nasce em Tabocas com a chegada dos imigrantes sergipanos, mas esquecem de dizer que já existia uma população estabelecida em Ferradas, uma importante via de acesso na região, "porque era ali que os tropeiros e os viajantes ferravam os seus animais, os quais tinham que enfrentar as estradas lamacentas e pedregosas com destino à Imperial Vila de Vitória" (CAMPOS. 1981 p. 535).

Além de via de acesso, Ferradas sediava o aldeamento São Pedro de Alcântara que, dentre suas funções, era responsável por estabelecer contato entre os indígenas aldeados e os mais afastados do litoral. Seria praticamente impossível que os imigrantes se

\footnotetext{
8 Apud MAHONY. 2007, p. 778.
} 
estabelecessem na região sem o papel pacificador dos indígenas aldeados. Na primeira parte de sua obra, José Dantas de Andrade cita Silva Campos que relata a dificuldade de sertanistas penetrarem as terras da Capitania de São Jorge dos Ilhéus, no início do século XVIII, por causa dos índios que habitavam a região: os botocudos, os pataxós e os camacans.

Em sua obra, Documentário histórico ilustrado de Itabuna, José Dantas de Andrade fala da dificuldade daqueles sertanistas, mas acentua que, aos poucos, devido a sua bravura, conseguiam algum progresso no que diz respeito a vencer a mata. Cita ainda a transferência do aldeamento localizado às margens do rio Almada para Ferradas, em 1815, pelo então governador da Província da Bahia - o Conde dos Arcos. No entanto, o relato do aldeamento de Ferradas é feito apenas para falar do trabalho catequético dos frades capuchinhos. Em nenhum momento confere alguma importância ao trabalho dos indígenas aldeados no processo de colonização daquelas terras.

Paralelo ao nascimento de Tabocas, os autores de 1960 descrevem o estado de decadência em que estaria imerso Ferradas. Para descrever o arraial de Tabocas como o grande propulsor do progresso, que estaria reservado à Itabuna, esses autores massificaram uma memória, na qual Ferradas teria um lugar apenas no passado. Seria um passado selvagem e, por isso, sem êxito. Era Ferradas de Frei Ludovico de Livorno, ou seja, uma aldeia de índios. Em oposição aos relatos apaixonados sobre o desenvolvimento de Tabocas, para a narrativa tradicional, Ferradas "parou como vila, acabaria como um simples arraial ou mesmo como uma rua comprida, acompanhando o rio Cachoeira." (PEREIRA FILHO, 1960, p. 27).

Atribuir a Ferradas alguma importância política, econômica e cultural seria reconhecer a importância do elemento indígena, ao lado do elemento imigrante, no lugar da memória local. Isso não interessava aos grupos dominantes da sociedade itabunense da década de 1960, visto que a memória social que deveria prevalecer seria a que Ihes legitimasse. Como afirma Hawlbachs, "o indivíduo depende das estruturas da memória social para trazer lembranças à mente" (HALBWACHS, 2004, p. 82). Essas lembranças, no caso da escrita da memória das origens de Itabuna, foram construídas e organizadas de acordo aos interesses dos grupos hegemônicos da cidade.

É uma tarefa difícil para a narrativa memorialista negligenciar o papel de agente histórico dos indígenas na história de origem de Itabuna. Mesmo quando descrevem o elemento indígena como entrave ao trabalho do imigrante, deixam indícios que nos permite perceber que o índio chegou antes no processo de ocupação das terras da região:

Mais para o interior, contudo, onde as matas ainda permaneciam invioladas, habitavam os Pataxós, os Camacans e os Baianans, que apesar de seu número reduzido eram os senhores absolutos dos cerrados, onde os 
pioneiros pouco se arriscavam (ANDRADE, 1968, p. 21).

Sem a aproximação e aliança que, pelos relatos descritos nessas narrativas, foram estabelecidas com os indígenas que povoavam a região, seria impossível considerar a permanência do não índio nessas terras. Tanto é que José Dantas de Andrade narra as estratégias de posseiros para manter aliança com os indígenas, ou seja, é impossível negar que diferentes grupos sociais se relacionaram no contexto da chegada de imigrantes à região.

O Sr. Pereira, exímio clarinetista, notou que os índios apreciavam sua música e passou a dar concertos exclusivos para eles, dedicando-lhes aquelas chorosas valsas antigas. $\mathrm{E}$, em troca, além de preservarem as plantações do seu músico, ainda Ihes traziam, de vez em quando, gordos exemplares de cotias, macucos, veados, os quais eram depositados, às escondidas, na porta de sua choça, todos com cartão de reconhecimento na própria flecha que os abatia (ANDRADE, 1968, p. 22).

Ao falar que os índios preservavam as plantações do Senhor Pereira, Andrade nos permite pensar que os indígenas que estabeleciam reciprocidade com os colonos eram os vizinhos habitantes de Ferradas, que os protegiam de prováveis ataques de populações indígenas mais afastadas. As relações de não índios e índios eram fundamentais para a acessibilidade dos primeiros a terra, contradizendo a memória construída, onde não há espaço para a ação de outros agentes históricos na história da origem de Itabuna.

A civilização grapiúna, a partir da narrativa da história local cristalizada pela memória regional, parte da idéia de que homens dispostos ao trabalho teriam chegado à região inóspita, selvagem e teriam plantado, aqui, através do seu suor, a semente do progresso: "Enquanto os índios recuavam para as matas, levas e levas de desbravadores se apoderavam das terras boas para o cacau, vindos de Ilhéus e do norte" (PEREIRA FILHO, 1960, p. 26). Nesse contexto, percebemos uma idéia de afastamento do que representaria e do que não representaria civilização: "os índios recuavam para as matas", significa dizer que os lugares sociais do índio e do imigrante não se encontram.

Na memória local não há espaço para protagonização de outros agentes históricos que não sejam os sergipanos de Tabocas, portadores do progresso de Itabuna. Já Ferradas era descrita como uma "velha localidade, que viu nascer e crescer Itabuna" (ANDRADE, 1968, 
p. 24) e, a ela, estaria reservado um lugar no passado, juntamente com os indígenas. Para que os discursos das elites política e intelectual da década de 1960 fossem legitimados, seria necessário manter Ferradas em uma memória remota, sem grande importância. Quando o autor diz que Ferradas viu nascer Itabuna, ele reitera a idéia de afastamento, não um distanciar físico apenas, mas, sobretudo, um afastamento da memória.

Pensar a história de fundação de Itabuna requer, portanto, pensar o papel da narrativa dos memorialistas que se dedicaram a escrever a história local. Quando Andrade diz: "Ao terminar a leitura deste documentário, os leitores verão que Itabuna foi uma Índia, que Félix Severino encontrou no mato e entregou ao seu sobrinho José Firmino Alves, o qual Ihe soube dar boa criação, educação, instrução e beleza" (ANDRADE, 1968, p. 18), o autor cristaliza uma história contada a partir dos interesses das elites de sua época, herdeiras dos grandes nomes e feitos das origens de Itabuna, narrativa que, por sua vez, marginalizara outros agentes históricos. Não obstante, esta história mítica vem sendo repetida pela escrita atual, inclusive a acadêmica, sem qualquer reflexão crítica.

Algumas considerações sobre o caráter de permanência do mito de origem de Itabuna e sobre a possibilidade de revisão historiográfica regional

Em A invenção das tradições, no capítulo intitulado "A produção em massa de tradições: Europa, 1870 a 1914". Hobsbawm disserta sobre a criação de tradições na Europa no período anterior à Primeira Guerra, tradições inventadas pelo poder público ou por grupos de indivíduos com interesses em comum, a fim de manter o controle social. Para o autor, as invenções de tradições eram:

(...) reflexos das profundas e rápidas transformações sociais do período. Grupos sociais, ambientes e contextos sociais inteiramente novos, ou velhos, mas incrivelmente transformados, exigiam novos instrumentos que assegurassem ou expressassem identidade e coesão social, e que estruturassem relações sociais (HOBSBAWM, 1997, p. 271).

Reportando a idéia de invenção de tradições como artifício e instrumento de controle de identidade social posta por Eric Hobsbawm para a história local, identificamos, nos espaços públicos urbanos de Itabuna, a construção de símbolos identitários, tais como monumentos, edificações arquitetônicas, praças e ruas que nos convidam a fazer uma leitura da cidade através de sujeitos históricos proeminentes, que representariam a própria história de Itabuna. 
Em um estudo sobre os símbolos de identidade social do centro da cidade de Itabuna, Lurdes Bertol Rocha, professora do curso de geografia da Universidade Estadual de Santa Cruz, pontua as principais edificações públicas que compõem a memória da cidade. Tomemos algumas como exemplo: a avenida Cinqüentenário, que na ocasião dos festejos do cinqüentenário da cidade passa a ser assim chamada, substituindo o antigo nome (rua J. J. Seabra); O edifício Comendador Firmino Alves, centro de decisões em relação a lavoura do cacau nas décadas de 50 e 60; O museu Casa Verde, que Rocha destaca por sua importância cultural para Itabuna, visto que retrataria a vida do coronelismo "onde foram reconstruídos os costumes e a época de uma das fases mais importantes da história regional" (ROCHA, 2003, p. 118); Praça Santo Antônio, local em que, no ano de 1944, foi inaugurado, no centro da praça, um monumento em homenagem à Firmino Alves; Praça Olinto Leone que, "até 1940 (...) era o coração administrativo, sócio-cultural e religioso da cidade" (ROCHA, 2003, p. 130); Praça José Almeida Alcântara, inaugurada em 1962 e tem como marco um monumento em homenagem ao então prefeito, cuja praça leva seu nome; Praça José Bastos que, segundo Bertol Rocha, recebe esse nome através de decreto de lei de 08 de junho de 1960. Além destes espaços apontados pela autora, podemos apontar, ainda, inúmeras ruas, escolas e outros espaços públicos que lembram os imigrantes que aqui chegaram a partir da segunda metade do século XIX e seus descendentes.

Identificados estes espaços, somos chamados a refletir sobre seu caráter de representação do lugar da memória das elites da cidade, que marcam o centro de Itabuna com seus nomes e feitos. Pelo exercício da tradição, "o jogo do lembrar e do esquecer fornece as referências temporais que o passado tem de assumir, a fim de poder produzir uma representação de continuidade instituidora de identidade" (RÜSEN, 2001, p. 84) e a versão das elites da cidade é apresentada à memória coletiva como representação da memória e da história local. Concomitantemente essas versões são repetidas, quando não pela preservação de monumentos, pela narrativa literária que, por sua vez, contribui para a permanência de discursos gestados pela memória oficial.

O relevante trabalho de Rocha (2003) reflete a preocupação com a pesquisa e, consequentemente, merece citação de quem se propõe a estudar os espaços urbanos da cidade de Itabuna. No entanto, comungando com o papel da historiografia regional tradicional, contribui para reforçar o mito histórico de Itabuna que conta a versão das elites do cacau como paradigma da história local. Rocha diz:

Apenas $1,8 \%$ dos entrevistados (...) citam o monumento localizado na praça Santo Antônio (...) como signos que lhes digam alguma coisa (...). Isto parece significar o total desconhecimento da história da cidade e, naturalmente, o não compromisso em relação à manutenção de sua 
memória (ROCHA, 2003, p. 125).

Sua fala reflete o papel da memória local, onde os sujeitos protagonistas das narrativas literárias e historiográficas têm seus nomes e feitos perpetuados pelo trabalho de controle da história regional. Em relação a este direcionamento, Mahony aponta que "o poder da mitologia da história do cacau reside no fato de que não é imposta, pois se apresenta espontaneamente como verdade nos vários estudos (...) publicados e repetidos indefinidamente por brasileiros e estrangeiros ao longo de todo o século XX" (MAHONY, 2007, p. 789).

Um bom exemplo atual de preservação da memória oficial é a obra de Adelino Kfoury Silveira (2002). O autor de Itabuna, minha terra! é escritor e se intitula também como historiador embora não tenha cursado história, atuou com membro do Instituto Geográfico e Histórico da Bahia, foi Sócio Titular da Associação Brasileira de Relações Públicas e Sócio Efetivo da Associação Baiana de Imprensa. Vale ressaltar que é proprietário de um considerável acervo particular e atuante na vida pública da cidade, tido como importante guardião da história local.

O autor critica a visão do coronel do cacau posta pela literatura (amadiana e adoniana), a qual o mesmo acusa de construir para esses homens um estereótipo de ambição e desonestidade. A fim de legitimar o lugar das elites do cacau como protagonistas da história de origem de Itabuna, o autor esforça-se em dizer que esses homens, ricos e poderosos, são os mesmos homens humildes, trabalhadores, corajosos e empreendedores que construíram o que é hoje Itabuna:

Qual seria, pois, a figura real do coronel do cacau? Achamos ser de justiça entender que ele foi acima de tudo um desbravador (...). Só mesmo a ação do tempo, o correr dos anos, fez com que esse exemplo de tenacidade gerasse o respeito e a obediência dos habitantes da região. Daí, num processo natural, foi chegando às suas mãos a riqueza e a força política (SILVEIRA, 2002, p. 14-15).

O autor segue a narrativa estabelecendo um distanciamento entre os "novos ricos"9 e a antiga aristocracia dos engenhos, ao dizer que haviam diferenças "a se considerar e estabelecer entre o nosso coronel e os senhores de engenho, é que ele vivia em casebres no âmago da floresta, dormindo em rede ou cama de esteira" (SILVEIRA, 2002, p. 15). Dessa maneira, Kfoury reforça o discurso dos memorialistas da década de 60 , de que a riqueza das

\footnotetext{
9 Termo de Mary Ann Mahony (2007).
} 
elites itabunenses eram heranças dos legítimos construtores de Itabuna, os desbravadores. Sobre o papel da narrativa histórica da região em transformar memória em história através da repetição da versão das elites do cacau, Mahony vai dizer:

\begin{abstract}
Em alguma medida, as pessoas acreditam na narrativa heróica porque reflete a experiência de algumas pessoas que vivem ou viveram na região. Os Berbert, os Castro, os Tavares, os Alves, assim como outros, ainda possuem propriedades produtoras de cacau e são evocados em histórias sobre a vida dos pequenos que deram certo na virada do século. Essas histórias são, por sua vez, repetidas nas casas, escolas, bares e escritórios de toda a região cacaueira (MAHONY, 2007, p. 786).
\end{abstract}

Em trabalho acadêmico de conclusão de curso, Santos (2000) toma a narrativa memorialista da região, sobretudo aquela produzida na década de 60 , como fonte bibliográfica e concomitantemente reproduz sem qualquer análise crítica o discurso impresso nessas obras. O autor descreve a estrutura metodológica do seu trabalho da seguinte maneira: "Num primeiro momento, foi feita uma retrospectiva da saga dos imigrantes sergipanos para o interior da Bahia, fundando o arraial de Tabocas, até a data de 28 de julho de 1910, quando a vila de Itabuna se torna uma rica e próspera cidade" (SANTOS, 2000, p. 23).

Em Memórias de Chico Benício (1985), o sergipano comerciante e fazendeiro, Francisco Benício dos Santos. Constrói uma narrativa onde a memória pretende atender a "imposição da própria ancestralidade, envolvendo a terra de origem (...), que embora a cultivassem com suor do rosto, nem sempre viram frutificar o seu trabalho" (SANTOS, 1985, p. 7).

A idéia de incorporação das origens humildes por parte das elites políticas, econômicas e intelectuais, continua, portanto, presente nas narrativas memorialistas de Itabuna a partir da década de 60. Parece elucidar bem essa evocação ao passado de humildade o seguinte fragmento da obra de Francisco Benício quando se refere à suas origens: "Desci, na verdade, à humildade em que elas se achavam plantadas, para de lá sair exaltado e envaidecido" (SANTOS, 1985, p. 8). Sua fala corresponde ao discurso gestado pela memória escrita, a fim de garantir aos descendentes dos imigrantes a legítima herança do que seus antepassados haviam construído. Sendo assim, a legitimidade do poder e riqueza dos antigos coronéis do cacau, residia num passado de trabalho dos fundadores da cidade.

Considerando que o elemento indígena a partir do trabalho de construção da memória social, tem povoado o imaginário e a escrita local como entrave à exploração das 
terras do sul da Bahia, onde dizer que "os índios: PATAXOS, GUERRENS, e CAMACÃS, dificultavam o trabalho de penetração do colono branco" (CARNEIRO, 1970, P. 01), é permitido pensar, a partir de um olhar crítico, fundamentado em novas perspectivas historiográficas regionais, que tal discurso, seria um esforço da memória oficial de marginalizar as populações indígenas do processo de formação de Itabuna, pois só há lugar nessa memória para a atuação dos imigrantes sergipanos que teriam como destino "conquistar a terra que, adormecia em sua virgindade, Ihes parecia indomável e invencível" (SANTOS, 1985, p. 9). Se nos deixássemos levar apenas por essas narrativas, sem uma devida contextualização regional, do período demarcado como a chegada de Félix Severino e parentes ao sul da Bahia, diríamos que aqui não havia presença humana e muito menos organização social antes dos sergipanos, quando na realidade pode-se comprovar que em Ferradas já havia, a partir da primeira metade do século XIX, uma considerável movimentação sócio-econômica graças ao trabalho dos indígenas do aldeamento São Pedro de Alcântara. Os indígenas que compunham o aldeamento "estavam posicionados nas regiões sul e sudoeste da Província da Bahia, entre as Bacias dos rios Pardo, Colônia/Cachoeira e das Contas eram nação Jê" (ANDRADE, 2003, p. 54).

Dias (2007), por sua vez, aponta para o protagonismo sócio-econômico dos grupos indígenas aldeados no processo de colonização do território da antiga capitania de llhéus. Tal possibilidade é apontada a partir de densa pesquisa sobre a região do sul da Bahia do período colonial desenvolvida pelo autor, que suscita reflexão sobre o suposto estado de estagnação econômica da antiga capitania de llhéus, recorrentemente repetido pela historiografia especializada. Pensar a organização e funcionalidade dos aldeamentos da capitania de llhéus é uma das possibilidades de reflexão historiográfica que emerge do trabalho de pesquisa do historiador.

Para Dias, os aldeamentos, espaços nos quais eram inseridos os índios estavam longe de se constituírem como local de alienação e passividade, pelo contrário, os aldeamentos serviram sim para resguardar a integridade física e a garantia de alguns direitos das populações indígenas. Nesses espaços, os índios eram dotados de autonomia, contradizendo a escrita tradicional de submissão indígena nos aldeamentos.

O autor discorre sobre a relevância do trabalho dos indígenas aldeados, que teriam contribuído para o desenvolvimento econômico da região. Os produtos do trabalho dos indígenas aldeados, não serviam apenas para subsistência das comunidades, mas, como bem mostra o denso trabalho de pesquisa desenvolvido pelo autor, o trabalho indígena era articulado às necessidades de mercado da região em atividades produtivas, extrativistas e artesanais desenvolvidas no interior dos aldeamentos. 
No sentido de dar visibilidade ao papel dos indígenas aldeados no processo de formação da região, o trabalho monográfico de Andrade sobre a ação dos capuchinhos na comarca de São Jorge Ilhéus, no século XIX, nos oferece pistas para refletir sobre a importância econômica e social do aldeamento de São Pedro de Alcântara nas Ferradas, lugar de repouso dos viajantes que iam em direção a vila imperial de Vitória da Conquista. $O$ autor aponta dados relevantes da participação do aldeamento na economia da região na primeira metade do século XIX, que podem ser comprovados pelas fontes do período:

O principal e mais importante destes aldeiamentos é o de S. Pedro d'Alcântara, situado á margem setentrional do Rio Cachoeira 12 léguas da Vila de Ilhéus (...). Esta aldeia tem hoje por missionário diretor o Frei Vicente de Ascoles, dotado de muita energia, que tem chamado os índios ao trabalho com perseverança fazendo plantar mais de 20.000 pes de café e 20.000 de cacau, e produzir farinha, arroz e feijão(...) , o que prova que esta Aldeia prospera (Jornal Falla - Bahia, 4 de julho de 1849, p. 34, Salvador. BA).

Os documentos disponíveis no arquivo público do Estado da Bahia enfatizam que os indígenas aldeados em Ferradas exerciam intensamente, atividades econômicas e não apenas de subsistência, o que deixa interrogações sobre o silenciamento da escrita histórica sobre uma organização econômica e social já existente antes da chegada dos imigrantes sergipanos na região do sul da Bahia.

\section{Considerações finais}

A historiografia tradicional tem repetido uma versão da história das origens de Itabuna que, com o suporte da memória, propõe uma identidade local que elege a atuação de apenas um grupo social no contexto de colonização daquele território. Com a emergência de novas pesquisas da história regional, surgem lacunas que não podem mais ser negligenciadas pela historiografia local. Nesse sentido, a proposta desse trabalho não foi desmerecer o papel dos imigrantes no processo de formação da cidade, mas, propor reflexão sobre a ausência de outros agentes históricos que também contribuíram na formação da região cacaueira.

É no mínimo intrigante que as populações indígenas, quando citadas, somente apareçam nos trabalhos memorialistas como entrave ao progresso da região e que, nos trabalhos mais recentes da história social e na história cultural, ganhem outra conotação. Com base na nova historiografia regional, seria mais plausível sugerir que o elemento indígena foi integrado à realidade local que se instalava a partir da segunda metade do 
século XIX, do que dizer que este, teria se afastado ou sido expulso.

Essa abordagem propõe uma problematização do papel indígena na formação econômica e social de Itabuna, possibilidade que, propositalmente ou não, foi negligenciada pela narrativa histórica ao longo do século XX. A abordagem desse trabalho prima em pensar não a história da origem de Itabuna, mas, as histórias das origens de Itabuna, no plural, enquanto um processo que envolveu múltiplos agentes na ocupação produtiva daquele território.

\section{Bibliografia}

ANDRADE, João Cordeiro. Missões Capuchinhas na Comarca de São Jorge dos Ilhéus (18161875). Monografia. Curso de História da Universidade Estadual de Santa Cruz (UESC); Ilhéus, 2003.

CAMPOS, João da Silva. Crônicas da Capitania de São Jorge dos Ilhéus. Rio de Janeiro: MECCFC, 1981.

CARVALHO, Philipe Murillo Santana. Uma cidade em disputa: conflitos e tensões urbanas em Itabuna (1930-1948). 2009, 175 f. Dissertação (Mestrado em História), Programa de Pósgraduação em História Regional e Local da Universidade do Estado da Bahia (UNEB), 2009.

DIAS, Marcelo Henrique. "A inserção econômica dos aldeamentos jesuíticos na capitania de Ilhéus". In: DIAS, Marcelo Henrique; CARRARA, Ângelo Alves (orgs.). Um lugar na história: a capitania e comarca de Ilhéus antes do cacau. Ilhéus: Editus, 2007.

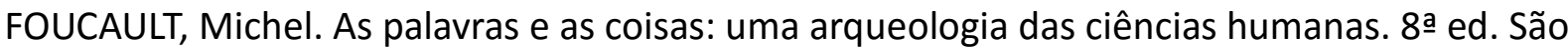
Paulo: Martins Fontes, 1999.

HALBWACHS, Maurice. A memória coletiva. São Paulo: Centauro, 2004A.

. A memória coletiva. São Paulo: Centauro, 2006B.

HOBSBAWM, Eric; RANGER, Terence (orgs.). A invenção das tradições. 6a ed. Rio de Janeiro: Paz e Terra, 1997.

. "A produção em massa de tradições: Europa, 1879 a 1914". In: HOBSBAWM, Eric; RANGER, Terence (orgs.). A invenção das tradições. 6a ed. Rio de Janeiro: Paz e Terra, 
1997, p. 271-316.

MAHONY, Mary Ann. Um passado para justificar o presente: memória coletiva, representação histórica e dominação política na região cacaueira da Bahia. Cadernos de Ciências HumanasEspeciaria, Ilhéus, v. 10, n. 18, p.737-793, jul.-dez. 2007.

PESAVENTO, Sandra Jatahy. "Em busca de uma outra história: Imaginando o imaginário". Revista Brasileira de História, ANPUH, São Paulo: Contexto, v. 15, n 29, 1995.

. História e história cultural. Belo Horizonte: Autêntica, 2005.

POLLAK, Michael. Memória, esquecimento, silêncio. Revista de Estudos Históricos, FGV, Rio de Janeiro: v.2, n3, p.3-15, 1989.

RIBEIRO, Danilo Ornelas. Do fazer jornalístico às sociabilidades de elites: a construção da Itabuna moderna (1957-1964). Monografia. Curso de História da Universidade Estadual de Santa Cruz (UESC); Ilhéus, 2010.

RÜSEN, Jörn. Razão histórica: teoria da história: fundamentos da ciência histórica. Brasília: Editora Universidade de Brasília, 2001.

THOMSON, Alistair; FRICH, Michael; HAMILTON, Paula. “Os debates sobre memória e história: alguns aspectos internacionais". In: AMADO, Janaína; FERREIRA, Maristela de Moraes (Orgs.). Usos e abusos da história oral. 4a ed. Rio de Janeiro: Editora FGV, 2001, p. 6591. 